\title{
Dissociative experiences in bipolar disorder II: Are they related to childhood trauma and obsessive-compulsive symptoms?
}

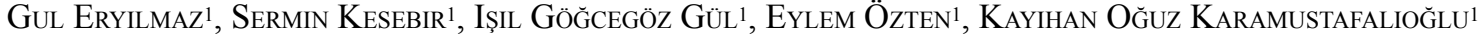 \\ 1 Uskudar University Neuropsychiatry Hospital, Psychiatry, Istanbul, Turkey.
}

Received: 12/29/2014 - Accepted: 3/2/2015

DOI: 10.1590/0101-60830000000045

\begin{abstract}
Objective: The aim of this study is to investigate the presence of dissociative symptoms and whether they are related to childhood trauma and obsessive-compulsive symptoms in bipolar disorder type II (BD-II). Methods: Thirty-three euthymic patients (HDRS $<8$, YMRS $<5$ ) and 50 healthy subjects were evaluated by SCID-I and SCID-NP. We excluded all first and second-axis comorbidities. All patients and healthy subjects were examined with the Dissociative Experiences Scale (DES), Childhood Trauma Questionnaire (CTQ-53), and Yale-Brown Obsessive-Compulsive Disorder scale (Y-BOCS). Results: In pairwise comparisons between the BD-II and control groups, the total CTQ, emotional abuse, emotional neglect, DES, and total Y-BOCS scores in the BD-II group were significantly higher than those in the control group $(\mathrm{p}<0.05)$. There were five cases with DES scores over $30(15.2 \%)$ and one case $(2 \%)$ in the control group. DES was weakly correlated with total CTQ and Y-BOCS in patients diagnosed with BD-II $(r=0.278, p<0.05$ and $r=0.217, p<0.05$, respectively). While there was no correlation between total CTQ and Y-BOCS, the CTQ sexual abuse subscale was found to be related to Y-BOCS ( $r=0.330$, $p<0.05$ ). Discussion: These results suggest that there is a relation between childhood traumas and obsessive-compulsive symptoms, or that dissociative symptoms are more associated with anxiety than obsessive symptoms, which prevents the increase of obsessive-compulsive symptoms in BD-II.
\end{abstract}

Eryilmaz G et al. / Arch Clin Psychiatry. 2015;42(2):38-40

Keywords: Bipolar disorder, childhood trauma, obsessive-compulsive symptoms, dissociative symptoms.

\section{Introduction}

Dissociation is clinically seen in different forms, such as dissociative amnesia, dissociative fugue, dissociative identity, derealization, and depersonalization ${ }^{1}$. Akyüz et al. reported that the prevalence of dissociative disorders was relatively low, in the general population in Turkey ${ }^{2}$. Sar et al. stated that the frequency of dissociative disorders among psychiatric outpatients in Turkey was $15.3 \%$, as indicated by a DES score greater than $30^{3}$.

Although dissociative symptoms are often seen in patients with mood disorders, there is little information on the possible association with childhood trauma and obsessive-compulsive symptoms of subgroups of these disorders. Dissociative processes are usually considered as sequelae of childhood trauma, although there are data to suggest that genetic influences are also important. $\mathrm{BD}$ is a condition with a strong genetic basis, and it has also been associated with early psychological trauma. Childhood trauma is a risk factor for both BD and dissociation ${ }^{4}$. Dissociative pathology discriminates between $\mathrm{BD}$ and dissociative disorder ${ }^{5}$. The literature has demonstrated that the level of dissociation might be correlated with the severity of obsessivecompulsive symptoms, and that those not responding to treatment have high dissociative symptoms ${ }^{6}$.

The aim of this study is to investigate the presence of dissociative symptoms and whether they are related to childhood trauma and obsessive-compulsive symptoms in bipolar disorder type II (BD-II). Our hypothesis was dissociation is more frequent in BD-II than healthy subjects and related to childhood trauma and obsession in BD-II.

\section{Methods}

\section{Sample and procedure}

The present study was performed between May and June 2014 in the Psychiatric Outpatient Department of Üsküdar University Health and Research Center. The Ethical Committee of Üsküdar University approved the study. Patients' written informed consent was obtained after the study protocol was thoroughly explained. One hundred patients diagnosed with BD-II according to DSM-IV were evaluated. SCID I and SCID II were used for diagnostic interviews. Fifty healthy subjects were evaluated by SCID-NP. Fifty-six patients who had comorbid axis I and II diagnoses and subthreshold depressive symptoms were excluded. Eleven patients gave invalid answers to the questionnaires. Thirty-three euthymic patients $(\mathrm{HDRS}<8, \mathrm{YMRS}<5$ ) were recruited. All patients and healthy subjects were examined with DES, the Childhood Trauma Questionnaire (CTQ-53), and the YaleBrown Obsessive-Compulsive Disorder Scale (Y-BOCS).

\section{Tools}

Dissociative Experiences Scale (DES): DES was developed by Bernstein and Putnam and includes 28 items $^{7}$. Each item is scored between 0 and 100, and the final score is obtained by calculating the average of the items. Scores over 30 indicate dissociative disorder. In a validity and reliability study performed in Turkey, high internal consistency was found based on the reliability of the scale (Cronbach alpha $=0.91)$ and test-retest correlation $(r=0.78)^{8}$.

Childhood Trauma Questionnaire (CTQ-53): CTQ-53 was developed by Bernstein as a 70-item scale in 1994, and it was reduced to 54 items in 1995. The questionnaire was adapted to Turkish by Şar in $1996^{9}$. It is a self-reported five-point Likert-type scale. It includes questions that assess emotional, physical, and sexual abuse, along with physical and emotional neglect in childhood. It also includes three questions for minimizing deception to evaluate the results more accurately. The answer options are (1) never, (2) rarely, (3) sometimes, (4) often, and (5) very often. Each question is scored between 1 and 5. The method allows each traumatic event subscale and total score to be calculated separately. The emotional abuse subscale is between 12 and 60, the physical abuse subscale is between 7 and 35, the sexual abuse subscale is scored between 7 and 35, the emotional neglect subscale is between 16 and 80 , and the physical neglect subscale is between 8 and 40. The total score is between 54 and 270. Cronbach alpha for factors related to each trauma type ranges from 0.79 to 0.94 showing high internal consistency. 
Yale-Brown Obsessive-Compulsive Symptom Scale (Y-BOCS): Y-BOCS is a reliable and valid clinician-administered 10-item scale that assesses the severity of obsessions and compulsions. Higher scores on Y-BOCS indicate greater severity. Total scores range from 0 to 40 , and scores for the obsession and compulsion subscales each range from 0 to 20 . The scale was developed in 1989 by Goodman and Price ${ }^{10}$ Its validity and reliability were confirmed by Tek et al. in $1995^{11}$.

\section{Statistical analysis}

Categorical variables were compared using the chi-square test, while numerical variables were compared with the Mann-Whitney $U$ test. The Pearson correlation test was used for correlation analysis. Statistical significance was set at $<0.05$, and all tests were two-tailed.

\section{Results}

According to the pairwise comparisons between the BD-II and control groups, the total CTQ, emotional abuse, emotional neglect, $\mathrm{DES}$, and total Y-BOCS scores in the BD-II group were significantly higher than those in the control group ( $p<0.05$, Table 1$)$. There were five cases with DES scores over 30 (15.2\%) and one case (2\%) in the control group.

DES was weakly correlated with total CTQ and Y-BOCS in patients diagnosed with BD-II $(r=0.278, p<0.05$ and $r=0.217$, $\mathrm{p}<0.05$, respectively). While there was no correlation between total CTQ and Y-BOCS, the CTQ sexual abuse subscale was found to be related to Y-BOCS $(\mathrm{r}=0.330, \mathrm{p}<0.05)$.

Table 1. Comparing between BD- $I I$ and $\mathrm{HC}$

\begin{tabular}{|c|c|c|c|c|}
\hline & $B D-11 n=33$ & $\mathrm{HC} n=50$ & Analysis $p$ \\
\hline \multicolumn{2}{|c|}{ Age (Mean \pm SD) } & $32.4 \pm 7$ & $30.5 \pm 7$ & 0.095 \\
\hline \multicolumn{2}{|c|}{$\begin{array}{l}\text { Gender }(n, \%) \\
\text { Male } \\
\text { Female }\end{array}$} & $\begin{array}{l}21,43.8 \\
27,56.3\end{array}$ & $\begin{array}{l}20,40 \\
30,60\end{array}$ & 0.445 \\
\hline \multicolumn{2}{|c|}{ DES (Mean \pm SD ) } & $17.6 \pm 14$ & $11,03 \pm 8.7$ & 0.03 \\
\hline \multirow{6}{*}{$\begin{array}{l}\text { CTO } \\
\text { (Mean } \\
\pm \text { SD }\end{array}$} & \begin{tabular}{|l}
$\begin{array}{l}\text { Emotional } \\
\text { abuse }\end{array}$ \\
\end{tabular} & $7.6 \pm 3$ & $6 \pm 1.4$ & 0.02 \\
\hline & \begin{tabular}{|l|} 
Emotional \\
neglect
\end{tabular} & $8.7 \pm 3.4$ & $6.8 \pm 2.4$ & 0.01 \\
\hline & \begin{tabular}{|l|}
$\begin{array}{l}\text { Physical } \\
\text { abuse }\end{array}$ \\
\end{tabular} & $5.2 \pm 1$ & $6.4 \pm 1.5$ & 0.84 \\
\hline & \begin{tabular}{|l|} 
Physical \\
neglect
\end{tabular} & $7.3 \pm 1.4$ & $6.4 \pm 1.5$ & 0.67 \\
\hline & \begin{tabular}{|l|}
$\begin{array}{l}\text { Sexual } \\
\text { abuse }\end{array}$ \\
\end{tabular} & $6.2 \pm 2.4$ & $6.5 \pm 2.4$ & 0.60 \\
\hline & Total CTO & $36.1 \pm 8$ & $29.7 \pm 4.7$ & 0.002 \\
\hline \multicolumn{2}{|c|}{ Y-BOCS (Mean \pm SD) } & $22 \pm 15$ & $9.5 \pm 10$ & 0.001 \\
\hline
\end{tabular}

\section{Discussion}

The DES score was found to be higher in patients diagnosed with BD-II than in healthy controls. These results are similar to a study by Latalova et al., who found the DES score to be higher in a mixed group of patients diagnosed with bipolar type I (BD-I) and BD-II patients compared with controls ${ }^{12}$. They examined 41 patients with $\mathrm{BD}$ in terms of dissociative symptoms, which were found significantly more frequently in the BD group than the healthy control group. In the same study, $51.2 \%$ of the BD group and $23.7 \%$ of the control group scored over 30 on the DES scale. In another study, dissociative experiences differentiated BD-II from unipolar depressed patients ${ }^{13}$. In a recent study, dissociative symptoms were operationalized as a risk factor for a new risk assessment instrument ${ }^{14}$. DES scores were similar between BD-I and BD-II ${ }^{15}$.
It was reported that emotional neglect in patients with $\mathrm{BD}$ was significantly more frequent than in the control group ${ }^{16}$. In our study, patients diagnosed with BD-II had higher emotional neglect and abuse scores than the controls. The same results are informed for patients diagnosed with BD-I. Childhood trauma in BD was associated with clinical characteristics such as an increase in psychotic symptoms, excess of mood episodes, and increase in suicidal thoughts and attempts ${ }^{16}$. There was also a significant relationship between sexual abuse and dissociative symptoms.

There was a weak correlation between DES and total CTQ score in the present study. It has been reported that traumatic experiences may affect Hypothalamic Pituitary Adrenal (HPA) axis dysregulation and the development and plasticity of the hippocampus, amygdala, and prefrontal lobe17,18. These neurobiological changes may be able to change the severity of the disease and affect the clinical effect of childhood trauma ${ }^{19}$. The relationship between childhood abuse and dissociation is influenced by catechol-O-methyltransferase (COMT) activity $^{4}$, Latalova et al. found highly statistically significant negative correlations between the level of dissociation measured by DES and most of the parameters of the autonomic nervous system in euthymic bipolar patients ${ }^{12}$.

Several studies confirmed the close association between depressive symptoms and dissociation ${ }^{20-22}$. Dissociation is correlated more strongly with checking and obsessive intrusions than with cleaning, ordering, and hoarding 6 . Moreover, these associations remained substantial even after controlling for neuroticism and other types of anxiety. In our study, there was no relation between DES and Y-BOCS. These results suggest that there is a relation between childhood traumas and obsessive-compulsive symptoms, or that dissociative symptoms are more associated with anxiety than obsessive symptoms, which prevents the increase of obsessive-compulsive symptoms ${ }^{23}$. Additionally, while there was no correlation between total CTQ and Y-BOCS, the CTQ sexual abuse subscale was found to be related to Y-BOCS. The identification of these symptoms may have important implications for better definition of clinical endophenotypes. For example, Mula et al. suggested that lifetime depersonalization symptoms are correlated with an early onset of BD and derealization symptoms with panic disorder comorbidity, which gives the opportunity to identify patients with a specific profile for a better clinical and neurobiological definition ${ }^{15}$.

The most obvious limitation of our study is the usage of three self-reported scales (DES, CTQ, and Y-BOCS). Also, according to some authors, very different features differentiate bipolar illness from borderline personality (dissociative symptoms, sexual trauma, and parasuicidal self-harm) ${ }^{24}$. The term disorder obfuscates an ontological difference between diseases (such as manic-depressive illness) and clinical pictures (such as hysteria, post-traumatic stress disorder, dissociation, and borderline personality). In our study, we excluded all first and second-axis comorbidities. Our results suggest that there is a relation between childhood traumas and obsessive-compulsive symptoms, or that dissociative symptoms are more associated with anxiety than obsessive symptoms, which prevents the increase of obsessive-compulsive symptoms. Results of this study suggested that dissociation is more frequent in BD-II than healthy subjects and related to childhood trauma and obsession in BD-II.

\section{References}

1. Blevins CA, Weathers FW, Witte TK. Dissociation and posttraumatic stress disorder: a latent profile analysis. J Trauma Stress. 2014;27:388-96.

2. Akyüz G, Dog]an O, Şar V, Yargıç Lİ, Tutkun H. Frequency of dissociative identity disorder in the general population in Turkey. Compr Psychiatry. 1999;40:151-9.

3. Sar V, Tutkun H, Alyanak B, Bakim B, Baral I. Frequency of dissociative disorders among psychiatric outpatients in Turkey. Compr Psychiatry. 2000;41:216-22.

4. Savitz JB, van der Merwe L, Newman TK, Solms M, Stein DJ, Ramesar RS. The relationship between childhood abuse and dissociation. Is it influenced by catechol-O-methyltransferase (COMT) activity? Int J Neuropsychopharmacol. 2008;11(2):149-61. 
5. Nijenhuis ER, Spinhoven P, van Dyck R, van der Hart O, de Graaf A, Knoppert EA. Dissociative pathology discriminates between bipolar mood disorder and dissociative disorder. Br J Psychiatry. 1997;170:581.

6. Watson D, Wu KD, Cutshall C. Symptom subtypes of obsessive compulsive disorder and their relation to dissociation. J Anxiety Disord. 2004;8:435-58.

7. Bernstein EM, Putnam PW. Development, reliability and validity of a dissociation scale. J Nerv Ment Dis. 1986;174:727-35.

8. Yargıç LI, Tutkun H, Şar V. The reliability and validity of the Turkish version of the dissociative experiences scale. Dissociation. 1995;8:10-3.

9. Sar V, Öztürk E, İkikardeş E. Validity and Reliability of the Turkish Version of Childhood Trauma Questionnaire. J Med Sci. 2012;32:1054-63.

10. Goodman WK, Price LH. The Yale-Brown Obsessive Compulsive Scale. II. Validity. Arch Gen Psychiatry. 1989;46:1012-6.

11. Tek C, Uluğ B, Rezaki BG, Tanriverdi N, Mercan S, Demir B, et al. YaleBrown Obsessive Compulsive Scale and US National Institute of Mental Health Global Obsessive Compulsive Scale in Turkish: reliability and validity. Acta Psychiatr Scand. 1995;91:410-3.

12. Latalova K, Prasko J, Pastucha P, Grambal A, Kamaradova D, Diveky $\mathrm{T}$, et al. Bipolar affective disorder and dissociation--comparison with healthy controls. Biomed Pap Med Fac Univ Palacky Olomouc Czech Repub. 2011;155:181-6.

13. Oedegaard KJ, Neckelmann D, Benazzi F, Syrstad VE, Akiskal HS, Fasmer OB. Dissociative experiences differentiate bipolar-II from unipolar depressed patients: the mediating role of cyclothymia and the Type A behaviour speed and impatience subscale. J Affect Disord. 2008;108(3):207-16.

14. Leopold K, Ritter P, Correll CU, Marx C, Özgürdal S, Juckel G, et al. Risk constellations prior to the development of bipolar disorders: rationale of a new risk assessment tool. J Affect Disord. 2012;136(3):1000-10.
15. Mula M, Pini S, Preve M, Masini M, Giovannini I, Cassano GB. Clinical correlates of depersonalization symptoms in patients with bipolar disorder. J Affect Disord. 2009;115(1-2):252-6.

16. Larsson S, Aas M, Klungsøyr O, Agartz I, Mork E, Steen NE, et al. Patterns of childhood adverse events are associated with clinical characteristics of bipolar disorder. BMC Psychiatry. 2013;22:13:97.

17. Heim C, Mletzko T, Purselle D, Musselman DL, Nemeroff CB. The dexamethasone/corticotropin-releasing factor test in men with major depression: role of childhood trauma. Biol Psychiatry. 2008;63:398-405.

18. Bremner JD. The relationship between cognitive and brain changes in posttraumatic stress disorder. Ann N Y Acad Sci. 2006;1071:80-6.

19. Heim C, Newport DJ, Heit S, Graham YP, Wilcox M, Bonsall R, et al Pituitary-adrenal and autonomic responses to stress in women after sexual and physical abuse in childhood. JAMA. 2000;284:592-7.

20. Lipsanen T, Saarijarvi S, Lauerma H. Exploring the relations between depression, somatization, dissociation and alexithymia--overlapping or independent constructs? Psychopathology. 2004;37:200-6.

21. Pastucha P, Prasko J, Diveky T, Grambal A, Latalova K, Sigmundova Z, et al. Borderline personality disorder and dissociation - comparison with healthy controls. ANSR 2009;51:146-9.

22. Boysan M, Goldsmith RE, Cavuş H, Kayri M, Keskin S. Relations among anxiety, depression, and dissociative symptoms: the influence of abuse subtype. J Trauma Dissociation. 2009;10:83-101.

23. Raszka M, Prasko J, Koprivova J, Novak T, Adamcova K. Psychological dissociation in obsessive-compulsive disorder is associated with anxiety level but not with severity of obsessive-compulsive symptoms. Neuroendocrinol Lett. 2009;30:624-8.

24. Ghaemi SN, Dalley S. The bipolar spectrum: conceptions and misconceptions. Aust N Z J Psychiatry. 2014;48(4):314-24. 